\section{O tempora, o virus}

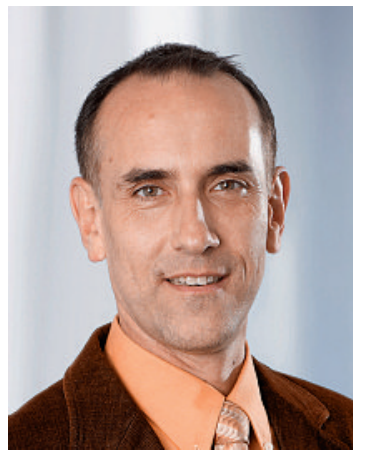

Frei nach Ciceros (106-43 v. Chr.) O tempora, o mores gibt die bevorstehende Influenza-Periode wieder einmal Anlass, vor dem «Verfall der Gesundheit» $\mathrm{zu}$ warnen. Denn es hüstelt, niest und schnieft bereits schon wieder heftig in Zügen, Trams und Bussen.

Pünktlich zur bevorstehenden Infektionsperiode durch das Grippevirus kam der Film «Contagion» in die Kinos. Dieser Actionthriller handelt vom Ausbruch eines tödlichen Virus und dem Versuch der Menschheit, sich global gegen dessen Ausbreitung mittels eines internationalen Teams von Ärzten zu wehren. Von den hochkarätigen Schauspielern hat man leider relativ wenig - sie werden meist innert Kürze dahingerafft, denn natürlich lässt sich das Virus nicht unter Kontrolle halten. Der Zuschauer wird mit verschiedenen Sicht- und Herangehensweisen von Ärzten, der medizinischen Versorgung und den Meinungen von Politikern zum Thema Pandemie und globalen Zusammenhängen konfrontiert.

\section{Eine neue Grippepandemie droht durchschnittlich alle 30 Jahre.}

Pandemien sind für die Bevölkerung längst keine Unbekannte mehr: Mit SARS (2002), Vogelgrippe (1996/2003) und H1N1 oder Schweinegrippe (2009) ist die Angst vor dem Ausbruch einer Viruserkrankung immer aktuell gewesen. Nach Erhebungen der Weltgesundheitsorganisation WHO droht eine neue Grippepandemie durchschnittlich alle 30 Jahre. Die bislang verheerendste Pandemie war die Spanische Grippe von 1918/19. Ihr Erreger war - wie bei der Schweinegrippe - eine Variante des H1N1-Grippevirus, der aber unmittelbar von einem Vogelgrippevirus abstammte. Diese Pandemie raffte innert weniger Monate um die 50 Millionen Menschen dahin, davon allein in Europa über 20 Millionen. Die Seuche forderte jedoch auch in Amerika, Japan, Indien $u$. a. Opfer. Insgesamt waren wohl rund 500 Millionen Menschen infiziert, was einem Drittel der damaligen Weltbevölkerung entsprach! *

In den Jahren 1996 und 2003 trat das Vogelgrippevirus (H5N1) auf - «nur» rund 400 Menschen sind daran gestorben, die meisten in Asien. Das Thema ist leider noch nicht abgeschlossen: auch dieses Jahr wurde bis September das hochpathogene aviäre Influenzavirus H5N1 bereits acht Mal auf den Menschen übertragen (u. a. in Indien, Indonesien). Und schliesslich wurde als letzte Pandemie 2009/10 das glo- bale Auftreten von Influenza-Erkrankungen definiert, die durch eine im Jahr 2009 entdeckte Influenzavirus-Variante des Typs A H1N1, Subtyp A/California/7/2009 und weiteren mit diesem genetisch eng verwandten Subvarianten hervorgerufen werden. Die Erkrankung ist allgemein unter den Namen Schweinegrippe und Neue Grippe bekannt.

Eine Prognose, ob eine Grippewelle sich zu einer Pandemie entwickeln kann, ist schwierig. Eine definitive Klassifi-

\section{Bis ein neuer Impfstoff zur Verfügung steht, braucht es rund fünf Monate Zeit.}

kation kann meist erst im Nachhinein erfolgen. Saisonale Grippevirenstämme registriert die WHO seit Jahrzehnten in einem Frühwarnnetz. Gemeinsam mit den Behörden koordiniert die WHO die Bedingungen für eine Zulassung neuer Impfstoffe und überwacht allfällige Resistenzen gegen Grippemedikamente.

Auch diesen Herbst stellt sich wieder die Frage: «Impfen oder nicht?» Bis ein neuer Impfstoff zur Verfügung steht, braucht es übrigens rund fünf Monate Zeit - zu viel Zeit bei einem akuten Auftreten eines hochvirulenten, mutierten Erregers, während der sich das Virus ungehindert ausbreiten kann. Schwere Verläufe sowie die Letalität der Influenza sind zum Teil mit einer bakteriellen Superinfektion assoziiert. Entsprechende prophylaktische und therapeutische Massnahmen zur Bekämpfung bakterieller Infektionen sind daher wichtige Methoden, um die Komplikationen inklusive der Sterblichkeit bei Influenza zu minimieren.

Eine Entwarnung zum Schluss: Lassen wir uns trotz aller medialen und cineastischen Beeinflussung nicht aus der Ruhe bringen, wenn es um uns herum hustet, tropft und keucht. Glücklicherweise handelt es sich in den meisten Fällen nicht um eine Grippe, sondern um einen «grippalen Infekt» - also eine Erkältung. Diese unechte Grippe macht uns im Schnitt fünfmal pro Jahr das Leben schwer. In drei Tagen kommt sie, drei Tage bleibt sie - und nach drei weiteren Tagen ist der Spuk bereits wieder vorbei.

In diesem Sinne wünsche ich schon einmal gute Besserung!

Dr. med. Gert Printzen, Mitglied des Zentralvorstandes, Verantwortlicher Ressort Heilmittel

* Weitere weniger katastrophale Grippepandemien waren die Asiatische Grippe von 1957, die weltweit auch noch immerhin zwei Millionen Tote forderte, und die HongkongGrippe von 1968, bei der etwa eine Million Menschen starben. 